\title{
Methods of calculating the belt foundation on the elastic ground base of winkler type
}

\author{
Anatoly Lastovka ${ }^{1, *}$, Tamara Danchenko ${ }^{1}$, Nadezhda Klinduh ${ }^{1}$, and Maria Berseneva ${ }^{1}$ \\ ${ }^{1}$ Siberian Federal University, 79 Svobodny Avenue, 660041, Krasnoyarsk, Russia
}

\begin{abstract}
Strip foundations on an elastic soil foundation and on a Winkler-type elastic foundation were used in the construction of buildings and structures from the most common types of shallow foundations. The article presents the results of studies related to the analysis of the features of the formation of structural solutions of strip foundations. It was found that various aspects associated with the development of multifactor mathematical models that determine the design parameters and modern regulatory requirements, provide conditions for not exceeding the limiting conditions of structures and soil base. It improves the functional quality indicators of strip foundations. Based on the results of the study, the need to study the possibilities of using strip foundations (beams on an elastic base) was identified, and the main provisions of the model of a Winklertype soil base (with one, two and three bed coefficients) were considered. An algorithm is developed for determining the initial parameters and numerical solution of boundary value problems. The prospects of a shallow foundation model with a variable cross section or a beam of finite length with variable stiffness, which is accepted as one of the options for modifying a typical structural solution of a strip foundation, are shown.
\end{abstract}

\section{Introduction}

The Winkler type of the elastic base is the most simplified model that takes into account the joint work of the above-ground structure and the elastic base (figure 1).

Any construction begins with the foundation. This is one of the important moments of the construction of a building or structure. All loads from the overlying structures it perceives and transmits it to the foundation base, except the transmitting loads must meet the requirements of durability reliability and be economically justified. Elastic base - the soil on which the foundation is located. Physical properties of soils are determined by a large number of parameters. When calculating, the elastic base is replaced by a simplified calculation model. The most common model of all proposed is the proportionality between the load applied at a given point of the base surface and the sediment of the same point of the elastic base. The essential difference between the models, in each case, is the distribution of reactions occurring between the foundation and the base.

\footnotetext{
* Corresponding author: ALastovka@,sfu-kras.ru
} 


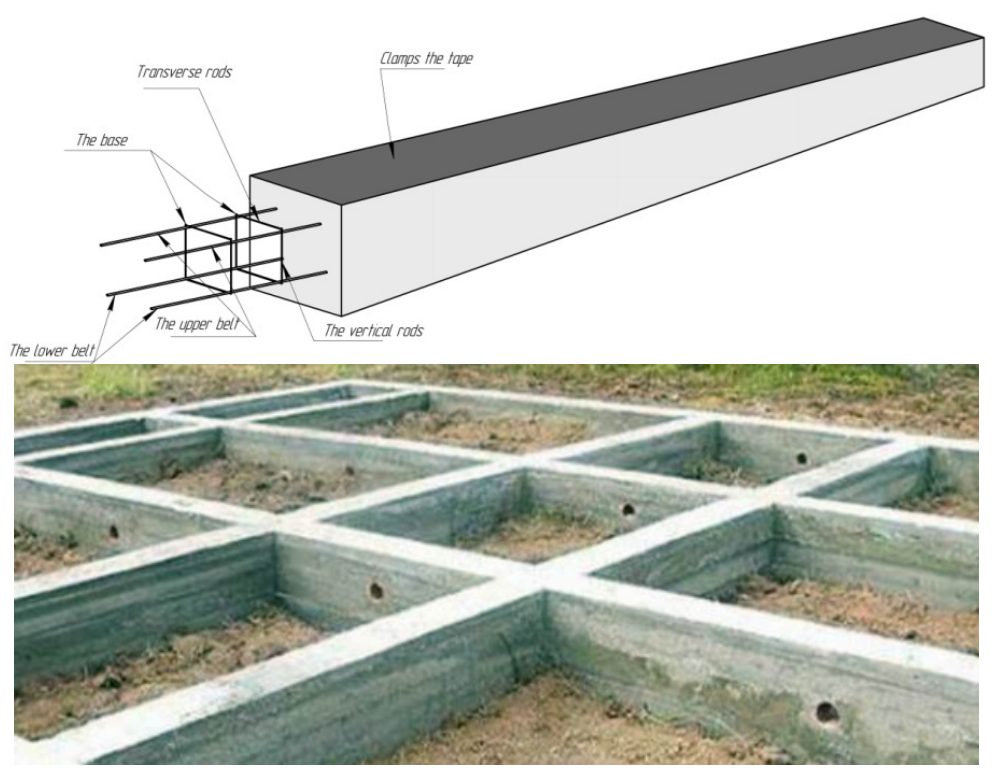

Fig. 1. Belt foundations (upper picture - designed by author; bottom picture - designed by designbyhand.ru)

\section{Features of design solutions of belt foundations}

The constructive decision of the foundation is made on the basis of the results of the analysis of the corresponding calculation (mathematical) model, which provides for the use of the following main groups of factors SP 22.13330.2016 Foundations of buildings and structures. Russian State Standard SNiP 2.02.01-83 * Updated version. - Moscow: Ministry of construction and housing and communal services of the Russian Federation, Order No. 970 of 16.12.2010. 2016. - 206 page.

* engineering-geological and hydrogeological conditions of the area of location (construction site);

- features of the structural scheme of the construction object;

- calculation combinations (magnitude and nature of operating loads);

- opportunities of local contracting (construction) organizations and enterprises of the construction industry;

- conditions of minimization of expenses of the building materials necessary for the device of the foundations;

- calculation of constraints on the stress state of the structure, contact pressure, deflection and uneven precipitation;

- requirements of operational reliability and functional efficiency.

\section{Low-depth belt foundation}

Shallow foundations are effective only in cases where the soil on the construction site does not belong to the category of heaving, as well as under the condition of low groundwater 
level (otherwise it is better to use pile). It goes without saying that if you build the base of the house on unstable soil, as well as soil that rises unevenly in winter, the belt foundation (no matter how well it was reinforced) will crack, which will lead to the destruction of the building, which is built on it. On such foundations it is recommended to erect light structures of houses. Brick two-storey cottages can be built only under the condition of nonporous soil on the site.

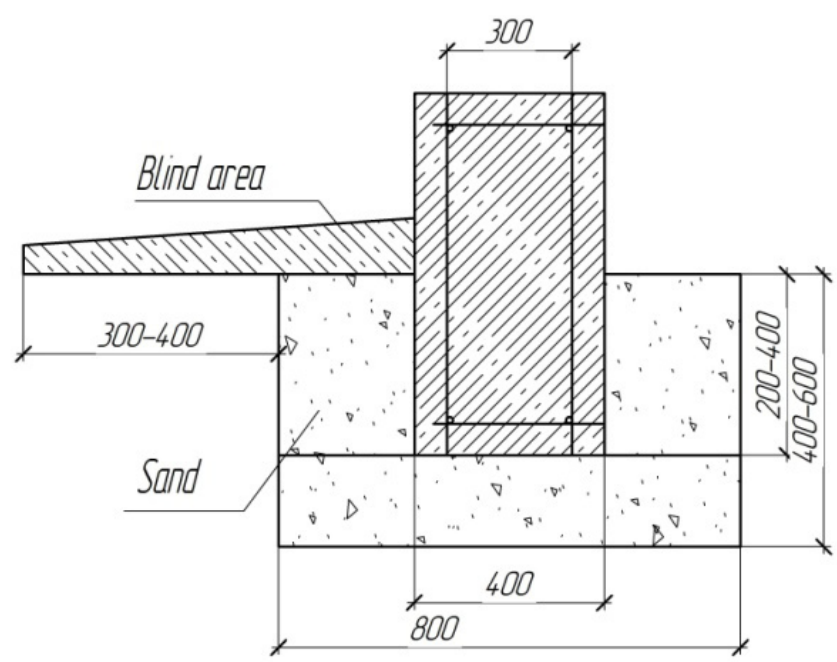

Fig. 2 Low-depth belt foundation (designed by author)

Belt foundations typologically belong to the group of "shallow foundations" and are used to transfer the load (calculated combination of load) from the vertical load-bearing structural elements (bearing and/or self-supporting walls) of a frameless structural system or rows of columns of a frameless structural system [3,4]. Structural solutions of belt foundations of precast concrete blocks-pillows (in the format: solid, ribbed and hollow) plates and concrete wall blocks allow laying on the ground base continuous (continuous belt) and intermittent (with the device gaps between adjacent plates) methods. Structural solutions of belt foundations of monolithic reinforced concrete slabs and walls allow laying on the ground base exclusively continuous (continuous belt) method.

Reinforcement of belt foundations is made using rod reinforcement of periodic profile: in the conditions of factory production (for belt foundations made of precast concrete) or in the conditions of the construction site (for belt foundations made of monolithic reinforced concrete).

Structural solutions of belt foundations (both in prefabricated and monolithic execution formats) are adopted based on the conditions of non-exceeding of its limit states [2, 4].

The load (more precisely, the calculated combination of loads) applied to the foundation structure should not exceed the forces and deformations in the belt foundation, as well as exceed the carrying capacity (or the force of the ultimate resistance) of the soil foundation.

Development of constructive solutions of the considered type of the foundation of small laying implies an assessment of joint work of the belt foundation and the soil base, taking into account features of the model of the soil base accepted for consideration. 


\section{Characteristics of the Winkler-type soil base model}

Modeling is a modern method of studying the behavior of the projected object of research on some key features. For practical application of the method, the formation of such an object of research is provided - a model that fully or with a sufficient degree of assumptions corresponds to the characteristics of the real object.

Characterization of indicators of stress-strain state of the soil base is a complex task, therefore, to simplify its solution (for practical activities), several mathematical models have been developed [2,3,17].

One of the simplest models of behavior of the soil base, designed to solve a wide range of problems, is considered to be a one-constant model of local elastic deformations of the soil base (Winkler model) [5,6].

In the considered mathematical model, it is assumed that the sediment of a certain point of the soil base is proportional to the pressure at this point:

$$
p(x)=K p \cdot W(x) \text {. }
$$

where: Kp-the coefficient of proportionality (constant coefficient characterizing the stiffness of the base), which is called the coefficient of strength of the soil base $(\mathrm{kPa} / \mathrm{m})$.

Under the characteristic $\mathrm{p}(\mathrm{x})$ in the calculated dependence (1), the generalized value of the load (concentrated force, bending moment distributed along the pressure line) is assumed, and under the characteristic $\mathrm{W}(\mathrm{x})$, the generalized value of deformation (linear displacement, rotation) is meant.

The coefficient of rigidity of the elastic base (in the calculated dependence (1)) characterizes the stiffness of the "spring" located at each point of the belt foundation. Deformation of the "springs" (located uniformly along the length of the belt foundation) occur independently of each other, therefore, the model does not take into account the distribution capacity of the soil, including, and beyond the contact area of the foundation with the soil base.

Determination of the calculated values is made using laboratory studies (with subsequent adjustment using the established correlation coefficients) or field tests of the base soils for compressibility.

Experimental (laboratory and field) studies show that the best way the Winkler model displays the stress-strain state of the soil base. The base consists of weak (silty, peat) types of soils and fine-grained water-saturated sands. In the presence of a soil base represented by connected soils, the Winkler model significantly distorts the real indicators of the state and operation of the foundation structure on a soil base $[3,5,18]$.

The main drawback of the Winkler model (with a single coefficient of rigidity of the elastic base) is the objective inadequacy of displaying the real state with which the structures of the belt foundation and the underlying soil foundation interact.

To correct the shortcomings of the model, a number of its modifications were developed - with two or three coefficients of rigidity of the elastic base. In domestic practice, the most common model of Pasternak with two coefficients of rigidity of the elastic base. The model of the Winkler base with additional (more than one) coefficients of rigidity of the elastic base allows to take into account the action of both normal and tangential stresses acting on the sole of the foundation [7].

The considered models of the soil base (with one, two and three coefficients of rigidity of the elastic base) characterize the deformed state by means of linear deformations (displacements) exclusively at the sites of load application and do not provide information about the distribution of stresses and strains in the soil base array. This circumstance means the lack of opportunities for correct accounting of the structure (stratification of soils with different physical and mechanical characteristics) and uneven resistance of the soil base over the entire area of contact with the plate (sole) of the foundation. 


\section{Theory of calculation of beams (belt foundations) on an elastic base using the method of initial parameters}

Traditional or analytical methods of calculation of belt foundations are developed and focused on the application of models and methods of calculation of foundations using the basic parameters of influence and mathematical apparatus that allows to reduce the results of research to the form suitable for engineering practice (for example, tables and coefficients).

The computational and theoretical model of the interaction of the structure of the belt foundation located on a solid ground base can be compiled and considered taking into account the hypothesis (theoretical provisions) of the beam work on an elastic base.

An elastic (Winkler) base is a base of a beam (foundation structure) that is deformed under the action of the calculated combination of the applied load and thus exerts an elastic counteraction to the deformation (deflection) of the base $[3,8]$.

The method of initial parameters is widely used to solve various classes of problems of mechanics, including problems related to the determination of the parameters of the stressstrain state of beams on an elastic base [9].

The differential equation of the curved axis of the beam (belt foundation) on an elastic base is represented as $[8,9]$ :

$$
E J \frac{d^{4} W}{d x^{4}}+K p \cdot W(x)=p(x)
$$

where: $\mathrm{Kp}-$ coefficient of rigidity of the elastic base

The main feature of the analytical interpretation of the method of initial parameters is the ability to analyze the parameters of the stress-strain state of the beam on an elastic base (under any of the possible types of load application and boundary conditions of fastening of the beam) by two known parameters (of the four possible: deflection, angle of inclination, bending moment and transverse force), which characterize the behavior of the curved axis of the beam.

Figure 3 shows one of the possible variants of the theoretical model of a beam (belt foundation) on an elastic base of the Winkler type.

The known initial parameters (in some arbitrary section of the beam, which is taken as the origin) are boundary conditions, and for the remaining unknown parameters, a system of linear equations is formed and solved.

The method of initial parameters is based on an analytical solution (determination of unknown parameters) in the form of a power series. At the same time, the considered method is available for algorithmization and numerical modeling by solving the boundary value problem. 


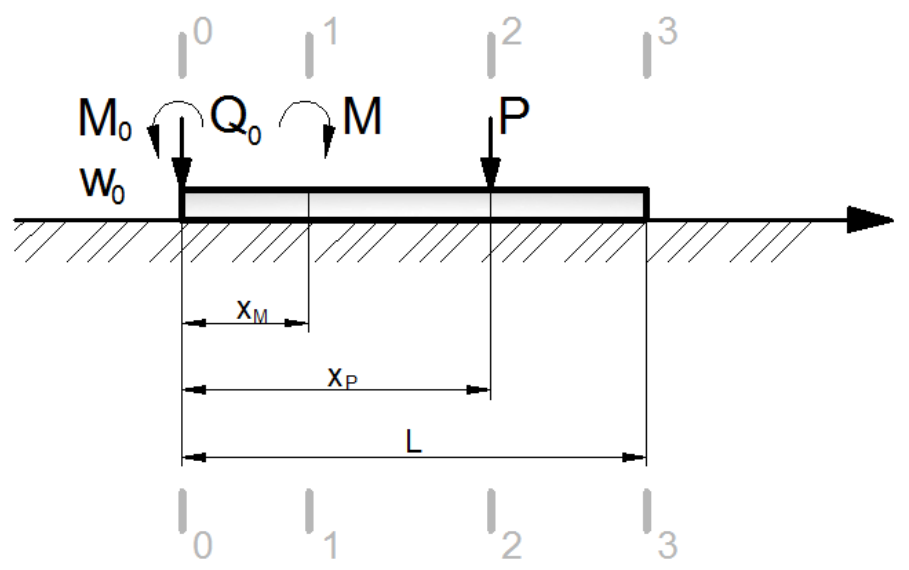

Fig. 3 The design scheme of the belt foundation in the format (model) of the beam of finite length on the elastic (Winkler) base, loaded: deflection, angle of rotation, bending moment, concentrated force (designed by the author)

\section{Conclusion}

Thus, it should be noted belt foundations on an elastic basis of the Winkler type, have been used in the construction of buildings and structures among the most common types of foundations of shallow laying. The method of calculation of belt foundations on a complex elastic base (with several coefficients of rigidity of the elastic base) of the Winkler type is proposed. The technique involves the implementation of matrix calculations, which are not difficult to carry out with the help of computer programs. Implementation. The proposed method is used to calculate the underground structure at an industrial enterprise. The technique allows taking into account more fully the actual work of the foundation structure located on the elastic base of the Winkler type. The theoretical economic effect of the introduction of the proposed technique reaches thirty-five percent due to savings in building materials. To complete the implementation and confirm the intended effect, it is necessary to build a facility and conduct full tests. Now about the advantages, belt shallow foundation is an economical solution. If you compare it with the buried species, it costs 2-3 times cheaper. It involves a significantly smaller front of work than the buried foundation. This can include a relatively small amount of excavation, and the complexity of the arrangement of formwork, and a number of other features. For the same reason, this solution can significantly reduce the time of construction of the house.

\section{References}

1. A.V. Lastovka Herald of the Eurasian Science 11 (3) 2019

2. D.A. Karnilov, A.P. Litikov, A.N. Mumortsev Engineering Bulletin of the Don. 4 1-10 (2014)

3. A.V. Matrosov, G.N. Shirunov Bulletin of the St. Petersburg University. Series 10. 2. 77-90. (2015)

4. N.D. Lodygina, R.V. Sharapov Bulletin of the Tambov University. Series: Natural and Technical Sciences. 5 (19) 1439-1441. (2014)

5. V.S. Glukhov, O.V. Khryanina, S.V. Glukhova Modern Scientific Research and Innovation. 12. 2016 
6. A.N. Kraev The rationale for the use of sand reinforced cushions in weak clay soils under strip foundations: abstract of the dissertation for the degree of candidate of technical sciences. Tyumen. (2014)

7. Yu.V. Naumkina Reinforcement of strip foundations with conversion to a continuous slab of variable stiffness with prestressing of the soil base: abstract of the dissertation for the degree of candidate of technical sciences. Tyumen (2014)

8. V.P. Dyba Materials of the Intern. scientific Forum / RSAU-ICCA. 3. 278 p. (2015)

9. M.P. Matvienko, V.P. Dyba, Al Yekabi Haki Hadi Abbud. Izv. universities. North Caucasus. region. Tech. Sciences. 3. 80-84. (2015)

10. S. Jha International Journal of Geomechanics. 16 (1). 1532-3641. (2016)

11. A. Sychova, A. Solomahin, A. Hitrov Procedia Engineering. 189. 688-694. (2017)

12. Chao Zhang et al. The 2017 World Congress on (ASEM17), (2017)

13. S. Stent et al., Machine Vision and Applications. 27 (3). 319-330. (2016)

14. Bo Shen et al., Hindawi Publishing Corporation International Journal of Distributed Sensor Networks. 11. (2015)

15. Rui Malva. Proceedings of the World Tunnel Congress 2014

16. K.I. Zarakovskaya, V.F. Zakharov Herald of the Eurasian Science, 4 (2018)

17. N.B. Gareeva, V.P. Rezvova, A.R. Tuigunova Bulletin of Eurasian Science, 2 (2019)

18. T. V. Danchenko, P. Y. Veda, E. V. Teselkin. Sat. articles I International scientific practical conference "Modern science: problems and prospects", 17-22 (2017) 